\title{
How to proceed
}

\section{when it comes to vitamin $\mathrm{D}$}

\section{USPSTF findings would support screening selective populations at risk for deficiency. But the value of supplements for prevention is nil or still unknown.}

Doug Campos-Outcalt, MD, MPA

University of Arizona,

Phoenix

$\Rightarrow$ dougco@email.arizona. edu

Dr. Campos-Outcalt is a member of the US Community Preventive Services Task Force.

doi: $10.12788 /$ ffp.0215
$\mathrm{I}$ n April 2021, the US Preventive Services Task Force (USPSTF) published an updated recommendation on screening for vitamin $\mathrm{D}$ deficiency in adults. It reaffirmed an "I" statement first made in 2014: evidence is insufficient to balance the benefits and harms of screening. ${ }^{1}$ This recommendation applies to asymptomatic, community-dwelling, nonpregnant adults without conditions treatable with vitamin D. It's important to remember that screening refers to testing asymptomatic individuals to detect a condition early before it causes illness. Testing performed to determine whether symptoms are evidence of an underlying condition is not screening but diagnostic testing.

The Task Force statement explains the problems they found with the current level of knowledge about screening for vitamin D deficiency. First, while 25-hydroxyvitamin D $[25(\mathrm{OH}) \mathrm{D}]$ is considered the best test for vitamin D levels, it is hard to measure accurately and test results vary by the method used and laboratories doing the testing. There also is uncertainty about how best to measure vitamin D status in different racial and ethnic groups, especially those with dark skin pigmentation. In addition, 25(OH)D in the blood is predominantly the bound form, with only $10 \%$ to $15 \%$ being unbound and bioavailable. Current tests do not determine the amount of bound vs unbound 25(OH)D. ${ }^{1-3}$

There is no consensus about the optimal blood level of vitamin D or the level that defines deficiency. The Institute of Medicine (now the National Academy of MedicineNAM) stated that serum 25(OH)D levels $\geq 20 \mathrm{ng} / \mathrm{mL}$ are adequate to meet the metabolic needs of $97.5 \%$ of people, and that levels of 12 to $20 \mathrm{ng} / \mathrm{mL}$ pose a risk of deficiency, with levels $<12$ considered to be very low. ${ }^{4}$ The Endocrine Society defines deficiency as $<20 \mathrm{ng} / \mathrm{mL}$ and insufficiency as 21 to $29 \mathrm{ng} / \mathrm{mL} .^{5}$

The rate of testing for vitamin $\mathrm{D}$ deficiency in primary care in unknown, but there is evidence that since 2000, it has increased 80 fold at least among those with Medicare. ${ }^{6}$ Data from the 2011-2014 National Health and Nutrition Examination Survey showed that $5 \%$ of the population had $25(\mathrm{OH}) \mathrm{D}$ levels $<12 \mathrm{ng} / \mathrm{mL}$ and $18 \%$ had levels between 12 and $19 \mathrm{ng} / \mathrm{mL}^{7}$ Some have estimated that as many as half of all adults would be considered vitamin D deficient or insufficient using current less conservative definitions, with higher rates in racial/ethnic minorities. ${ }^{2,8}$

There are no firm data on the frequency, or benefits, of screening for vitamin D levels in asymptomatic adults (and treating those found to have vitamin D deficiency). The Task Force looked for indirect evidence by examining the effect of treating vitamin D deficiency in a number of conditions and found that for some, there was adequate evidence of no benefit and for others there was inadequate evidence for possible benefits. ${ }^{9}$ No benefit was found for incidence of fractures, type 2 diabetes, and overall mortality. ${ }^{9}$ Inadequate evidence was found for incidence of cancer, 
TABLE 1

\section{Specific vitamin D-related topics addressed by the USPSTF}

\begin{tabular}{|c|}
\hline Falls in the elderly \\
\hline $\begin{array}{l}\text { The USPSTF recommends against vitamin D supplementation to prevent falls in community-dwelling adults } \geq 65 \text { years. } \\
\text { (D recommendation) }\end{array}$ \\
\hline Prevention of cardiovascular disease or cancer \\
\hline $\begin{array}{l}\text { Current evidence is insufficient to assess the balance of benefits and harms of the use of single- or paired-nutrient supplements } \\
\text { (including vitamin D) for the prevention of cardiovascular disease or cancer. (I statement) }\end{array}$ \\
\hline Prevention of fractures \\
\hline $\begin{array}{l}\text { Current evidence is insufficient to assess the balance of benefits and harms of vitamin D and calcium supplementation, alone } \\
\text { or combined, for the primary prevention of fractures in men and premenopausal women. (I statement) }\end{array}$ \\
\hline $\begin{array}{l}\text { Current evidence is insufficient to assess the balance of benefits and harms of daily supplementation with doses }>400 \text { IU of } \\
\text { vitamin D and }>1000 \mathrm{mg} \text { of calcium for the primary prevention of fractures in community-dwelling, postmenopausal women. } \\
\text { (I statement) }\end{array}$ \\
\hline $\begin{array}{l}\text { The USPSTF recommends against daily supplementation with } \leq 400 \mathrm{IU} \text { of vitamin } \mathrm{D} \text { and } \leq 1000 \mathrm{mg} \text { of calcium for the primary } \\
\text { prevention of fractures in community-dwelling, postmenopausal women. (D recommendation) }\end{array}$ \\
\hline
\end{tabular}

USPSTF, US Preventive Services Task Force.

cardiovascular disease, scores on measures of depression and physical functioning, and urinary tract infections in those with impaired fasting glucose. ${ }^{9}$

Known risk factors for low vitamin D levels include low vitamin D intake, older age, obesity, low UVB exposure or absorption due to long winter seasons in northern latitudes, sun avoidance, and dark skin pigmentation. ${ }^{1}$ In addition, certain medical conditions contribute to, or are caused by, low vitamin D levels-eg, osteoporosis, chronic kidney disease, malabsorption syndromes, and medication use (ie, glucocorticoids). ${ }^{1-3}$

The Task Force recommendation on screening for vitamin D deficiency differs from those of some other organizations. However, none recommend universal populationbased screening. The Endocrine Society and the American Association of Clinical Endocrinologists recommend screening but only in those at risk for vitamin D deficiency. ${ }^{5,10}$ The American Academy of Family Physicians endorses the USPSTF recommendation. ${ }^{11}$

Specific USPSTF topics related to vitamin D The Task Force has specifically addressed 3 topics pertaining to vitamin D. In each instance, the recommendation relates not to providing vitamin $\mathrm{D}$ to those who have vitamin $\mathrm{D}$ deficiency, but to providing vi- tamin D supplementation universally to specific groups at risk of a particular condition (TABLE 1).

I Prevention of falls in the elderly. In 2018 the Task Force recommended against the use of vitamin $\mathrm{D}$ to prevent falls in community-dwelling adults $\geq 65$ years. ${ }^{12}$ This reversed its 2012 recommendation advising vitamin D supplementation to prevent falls. The Task Force re-examined the old evidence and looked at newer studies and concluded that their previous conclusion was wrong and that the evidence showed no benefit from vitamin $\mathrm{D}$ in preventing falls in the elderly. The reversal of a prior recommendation is rare for the USPSTF because of the rigor of its evidence reviews and its policy of not making a recommendation unless solid evidence for or against exists.

I Prevention of cardiovascular disease and cancer. The Task Force concludes that current evidence is insufficient to assess the balance of benefits and harms in the use of single- or paired-nutrient supplements to prevent cardiovascular disease or cancer. ${ }^{13}$ (The exceptions are beta-carotene and vitamin $\mathrm{E}$, which the Task Force recommends against.) This statement is consistent with the lack of evidence the Task Force found regarding prevention of these conditions by vitamin D supplementation in those who are vitamin D deficient. 
TABLE 2

Recommended dietary allowances per day for vitamin $\mathrm{D}^{15}$

\begin{tabular}{l|l|l|l|l}
\hline Age & Male & Female & Pregnancy & Lactation \\
\hline $0-12 \mathrm{mo}$ & $10 \mathrm{mcg}(400 \mathrm{IU})$ & $10 \mathrm{mcg}(400 \mathrm{IU})$ & & \\
\hline $1-13 \mathrm{y}$ & $15 \mathrm{mcg}(600 \mathrm{IU})$ & $15 \mathrm{mcg}(600 \mathrm{IU})$ & & \\
\hline $14-18 \mathrm{y}$ & $15 \mathrm{mcg}(600 \mathrm{IU})$ & $15 \mathrm{mcg}(600 \mathrm{IU})$ & $15 \mathrm{mcg}(600 \mathrm{IU})$ & $15 \mathrm{mcg}(600 \mathrm{IU})$ \\
\hline $19-50 \mathrm{y}$ & $15 \mathrm{mcg}(600 \mathrm{IU})$ & $15 \mathrm{mcg}(600 \mathrm{IU})$ & $15 \mathrm{mcg}(600 \mathrm{IU})$ & $15 \mathrm{mcg}(600 \mathrm{IU})$ \\
\hline $51-70 \mathrm{y}$ & $15 \mathrm{mcg}(600 \mathrm{IU})$ & $15 \mathrm{mcg}(600 \mathrm{IU})$ & & \\
\hline$>70 \mathrm{y}$ & $20 \mathrm{mcg}(800 \mathrm{IU})$ & $20 \mathrm{mcg}(800 \mathrm{IU})$ & & \\
\hline
\end{tabular}

TABLE 3

Vitamin D content of selected foods ${ }^{15}$

\begin{tabular}{|c|c|c|c|}
\hline Food & mcg & IU & $\% \mathrm{DV}^{\mathrm{a}}$ \\
\hline Cod liver oil, 1 tablespoon & 34 & 1360 & 170 \\
\hline Trout (rainbow), farmed, cooked, 3 oz & 16.2 & 645 & 81 \\
\hline Salmon (sockeye), cooked, $3 \mathrm{oz}$ & 14.2 & 570 & 71 \\
\hline Mushrooms, white, raw, sliced, exposed to UV light, $1 / 2$ cup & 9.2 & 366 & 46 \\
\hline Milk, $2 \%$ milk fat, vitamin D fortified, 1 cup & 2.9 & 120 & 15 \\
\hline Soy, almond, and oat milk, vitamin D fortified, various brands, 1 cup & $2.5-3.6$ & $100-144$ & $13-18$ \\
\hline Ready-to-eat cereal, fortified with $10 \%$ of DV for vitamin $D, 1$ serving & 2 & 80 & 10 \\
\hline Sardines (Atlantic), canned in oil, drained, 2 sardines & 1.2 & 46 & 6 \\
\hline Egg, large, scrambled & 1.1 & 44 & 6 \\
\hline Liver, beef, braised, 3 oz & 1 & 42 & 5 \\
\hline Tuna (light), canned in water, drained, $3 \mathrm{oz}$ & 1 & 40 & 5 \\
\hline
\end{tabular}

DV, daily value; UV, ultraviolet.

a The Food and Drug Administration developed DVs to help consumers compare the nutrient content of foods and dietary supplements within the context of a total diet. The DV for vitamin D is $20 \mathrm{mcg}(800 \mathrm{IU})$ for adults and children ages 4 years and older. The labels must list vitamin D content in mcg per serving and have the option to also list the amount in IUs in parentheses. Foods providing $20 \%$ or more of the DV are considered to be high sources of a nutrient, but foods providing lower percentages of the DV also contribute to a healthful diet.

I Prevention of fractures in men and in premenopausal and postmenopausal women. For men and premenopausal women, the Task Force concludes that evidence is insufficient to assess the benefits and harms of vitamin D and calcium supplementation, alone or in combination, to prevent fractures. ${ }^{14}$ For prevention of fractures in postmenopausal women, there are 2 recommendations. The first one advises against the use of $\leq 400$ IU of vitamin D and $\leq 1000 \mathrm{mg}$ of calcium because the evidence indicates ineffectiveness. The second one is another "I" statement for the use of doses $>400$ IU of vitamin D and > $1000 \mathrm{mg}$ of calcium. These 3 recommendations apply to adults who live in the community and not in nursing homes or other institutional care facilities; they do not apply to those who have osteoporosis.

\section{What should the family physician do?}

Encourage all patients to take the recommended dietary allowances (RDA) of vitamin $\mathrm{D}$. The RDA is the average daily level of intake sufficient to meet the nutrient requirements of nearly all (97\%-98\%) healthy individuals. Most professional organizations recommend that adults $\geq 50$ years consume 800 to 1000 IU of vitamin D daily. TABLE 2 lists the RDA for vitamin D by age and sex..$^{15}$ The amount of vitamin $\mathrm{D}$ in selected food products is listed in TABLE $3 .^{15}$ Some increase in levels of vitamin $\mathrm{D}$ can occur as a result of sun exposure, but current practices of sun avoidance make it difficult to achieve a significant contribution to vitamin D requirements. ${ }^{15}$

CONTINUED 
Evidence is insufficient to recommend vitamin D and calcium supplementation, alone or in combination, to prevent fractures in men or premenopausal women.
I Alternatives to universal screening. Screening for vitamin D deficiency might benefit some patients, although there is no evidence to support it. Universal screening will likely lead to overdiagnosis and overtreatment based on what is essentially a poorly understood blood test. This was the concern expressed by the NAM.,16 An editorial accompanying publication of the recent USPSTF recommendation suggested not measuring vitamin D levels but instead advising patients to consume the age-based RDA of vitamin D. ${ }^{3}$ For those at increased risk for vitamin $\mathrm{D}$ deficiency, advise a higher dose of vitamin D (eg, $2000 \mathrm{IU} / \mathrm{d}$, which is still lower than the upper daily limit). ${ }^{3}$

Other options are to screen for vitamin $\mathrm{D}$ deficiency only in those at high risk for low vitamin D levels, and to test for vitamin $\mathrm{D}$ deficiency in those with symptoms associated with deficiency such as bone pain and muscle weakness. These options would be consistent with recommendations from the Endocrine Society. ${ }^{5}$ Some have recommended that if testing is ordered, it should be performed by a laboratory that uses liquid chromatography-mass spectrometry because it is the criterion standard. ${ }^{2}$

I Treatment options. Vitamin D deficiency can be treated with either ergocalciferol (vitamin $\mathrm{D}_{2}$ ) or cholecalciferol (vitamin $\mathrm{D}_{3}$ ). These treatments can also be recommended for those whose diets may not provide the RDA for vitamin D. Both are readily available over the counter and by prescription. The Task Force found that the harms of treating vitamin $\mathrm{D}$ deficiency with vitamin $\mathrm{D}$ at recommended doses are small to none. ${ }^{1}$ There is possibly a small increase in kidney stones with the combined use of $1000 \mathrm{mg} / \mathrm{d}$ calcium and $10 \mathrm{mcg}$ (400 IU)/d vitamin D. ${ }^{17}$ Large doses of vitamin D can cause toxicity including marked hypercalcemia, nausea, vomiting, muscle weakness, neuropsychiatric disturbances, pain, loss of appetite, dehydration, polyuria, excessive thirst, and kidney stones. ${ }^{15}$

A cautious evidence-based approach would be to selectively screen for vitamin D deficiency, conduct diagnostic testing when indicated, and advise vitamin D supplementation as needed.

JFP

\section{References}

1. USPSTF. Screening for vitamin D deficiency in adults: US Preventive Services Task Force recommendation statement. JAMA. 2021;325:1436-1442.

2. Michos ED, Kalyani RR, Segal JB. Why USPSTF still finds insufficient evidence to support screening for vitamin D deficiency. JAMA Netw Open. 2021;4:e213627.

3. Burnett-Bowie AAM, Cappola AR. The USPSTF 2021 recommendations on screening for asymptomatic vitamin D deficiency in adults: the challenge for clinicians continues. JAMA. 2021;325:1401-1402.

4. Institute of Medicine. Dietary reference intakes for calcium and vitamin D. National Academies Press; 2011. Accessed May 22, 2021. https://pubmed.ncbi.nlm.nih.gov/21796828/

5. Holick MF, Binkley NC, Bischoff-Ferrari HA, et al. Evaluation, treatment, and prevention of vitamin D deficiency: an Endocrine Society clinical practice guideline. J Clin Endocrinolgy Metab. 2011;96:1911-1930.

6. Shahangian S, Alspach TD, Astles JR, et al. Trends in laboratory test volumes for Medicare part B reimbursements, 2000-2010. Arch Pathol Lab Med. 2014;138:189-203.

7. Herrick KA, Storandt RJ, Afful J, et al. Vitamin D status in the United States, 2011-2014. Am J Clin Nutr. 2019;110:150-157.

8. Forrest KYZ, Stuhldreher WL. Prevalence and correlates of vitamin D deficiency in US adults. Nutr Res. 2011;31:48-54.

9. Kahwati LC, LeBlanc E, Weber RP, et al. Screening for vitamin D deficiency in adults: updated evidence report and systematic review for the US Preventive Services Task Force. JAMA. 2021;325:1443-1463.

10. Camacho PM, Petak SM, Binkley N, et al. American Association of Clinical Endocrinologists and American College of Endocrinology clinical practice guidelines for the diagnosis and treatment of postmenopausal osteoporosis-2016. Endocr Pract. 2016;22 (supp 4):1-42.

11. AAFP. Clinical preventive services. Accessed May 22, 2021. www.aafp.org/family-physician/patient-care/clinicalrecommendations/aafp-cps.html

12. USPSTF. Falls prevention in community-dwelling older adults: interventions. Accessed May 22, 2021. https:// uspreventiveservicestaskforce.org/uspstf/recommendation/ falls-prevention-in-older-adults-interventions

13. USPSTF. Vitamin supplementation to prevent cancer and CVD: preventive medication. Accessed May 22, 2021. https:// uspreventiveservicestaskforce.org/uspstf/recommendation/ vitamin-supplementation-to-prevent-cancer-and-cvdcounseling

14. USPSTF. Vitamin D, calcium, or combined supplementation for the primary prevention of fractures in community-dwelling adults: preventive medication. Accessed May 22, 2021. https:// uspreventiveservicestaskforce.org/uspstf/recommendation/ vitamin-d-calcium-or-combined-supplementation-forthe-primary-prevention-of-fractures-in-adults-preventivemedication

15. NIH. Vitamin D. Accessed May 22, 2021. https://ods.od.nih.gov/ factsheets/VitaminD-HealthProfessional/

16. Ross AC, Manson JE, Abrams SA, et al. The 2011 report on dietary reference intakes for calcium and vitamin D from the Institute of Medicine: what clinicians need to know. JClin Endocrinol Metab. 2011;96:53-58.

17. Jackson RD, LaCroix AZ, Gass M, et al. Calcium plus vitamin $\mathrm{D}$ supplementation and the risk of fractures. $N$ Engl J Med. 2006;354:669-683. 